\title{
Absolute time estimates as a function of complexity and interruption of melodies
}

\author{
JOY YEAGER.' Hartard Graduate School of Education. \\ Cumbridge, Ilass. 02138
}

Absolute time estimates were obtained to melodies having three degrees of complexity and two states of interruption (with and without rests). the melodies occurring at three durations. Although not statistically significant, mean time estimates were longer for more complex melodies and longer for uninterrupted melodies.

This is a study of duration estimates of melodies which varied in complexity and which occurred in two forms. one interrupted and the other uninterrupted by rests. The primary question was, do people give longer time estimates to more complex melodies than to simpler ones when the melodies are actually of equal duration? The secondary question was, do people give longer time estimates to uninterrupted melodies (without rests) than to interrupted ones (with rests) when the melodies are really equal in duration?

Whitely \& Anderson (1930) found that time estimates were shortest for intervals filled by a Strauss march, longer for intervals filled with the sound of a buzzer tone, and longest for intervals of silence. Their results could be interpreted as evidence against the idea that more complex melodies should elicit longer duration estimates than simpler ones. However, Loehlin (1959) found that college students who overestimated the time spent on certain tasks also rated those tasks as less interesting than students who underestimated those same tasks. Perhaps the Strauss march received shorter time estimates than the buzzer tone because it was more interesting.

The present experiment was designed to study the effects of complexity and interruptions on time estimates. The experiment required absolute time judgments of melodies. Three melodies were used: a monotone (simplest), a regular alternation of two pitches (more complex). and an irregular alternation of two pitches (most complex). The interrupted forms of the melodies had rests between notes, and the uninterrupted forms had continuous sound. The two forms of each melody occurred at three different objective durations.

\section{MELODIES}

There were two pitches used in the tonal sequences: " $F$ " $(349 \mathrm{~Hz})$ and middle " $\mathrm{C}$ " $(262 \mathrm{~Hz})$. The melodies occurred at 15-, 30-, and 45-sec durations. The melodies had a 1 time: one note in each bar, and the note was a whole note. This means that every note received the same stress. There were 21 bars and thus 21 beats in every melody. The duration of the whole note was determined by dividing the objective duration of the melody by 21 (bars or beats). Thus. the duration of a whole note was proportional for the three melody lengths. Specifically, the whole notes lasted $.71 \mathrm{sec}$ in the 15 -sec melodies, $1.43 \mathrm{sec}$ in the $30-\mathrm{sec}$ melodies, and $2.14 \mathrm{sec}$ in the 45-sec melodies.

Figure 1 is a graphic display of the melodies. The interrupted forms of the monotone and of the regular alternation sequences had about half the amount of sound and half the number of tone onsets as their uninterrupted forms. The interrupted form of the irregular alternation melody had about $3 / 4$ the sound duration and about $8 / 11$ the number of tone onsets as its uninterrupted form. Also, the interrupted form of the irregular alternation melody displayed only the first half of the pattern of the uninternupted form.

The melodies were generated on a PDP-4 computer and taped at 7.5 ips full-track on an Ampex taperecorder. Silences of $10 \mathrm{sec}$ occurred between consecutive melodies so that Ss could make a time estimate after each melody. DESIGN

Three different degrees of melodic complexity were used. and each melody occurred in both an internipted and an uninterrupted form. Both forms of each melody occurred at the real durations of 15,30 . and $45 \mathrm{sec}$. Each $S$ heard all 18 tonal forms and was thus his own control.

The 18 melodies were presented in four different orders. each order being heard by a different group of Ss. The melody-presentation orders were selected from a random digit table such that sequences of the same duration series $(15,30$. and $45 \mathrm{sec}$ ) could not occur consecutively. Each order started and ended with a different melody duration, state of interruption. and complexity.

There were 52 Ss. 13 people in each of four groups. one group for each order of melody presentation. Ss were unpaid volunteers associated with the Harvard Graduate School of Education. Ss heard the melodies from ceiling speakers in a quiet classroom. They wrote their time estimates in 18-page booklets. one page for each melody, during a 20 -min experimental session.

\section{RESULTS}

Table 1 shows the mean time estimates as a function of the real durations of the melodies $(15,30$, and $45 \mathrm{sec})$. complexity (monotone. regular alternation, and irregular alternation), and interruption (uninterrupted and interrupted).

The margins show that the mean time estimates became longer for more complex melodies and longer for the uninterrupted melodies. But the differences among the mean time estimates were extremely small. and within the table those differences were not uniformly in the predicted directions. The greatest differences in mean time estimates were a function of the objective durations of the melodies rather than of the complexity or state of interruption. The 45-sec melodies received longer time estimates than the 30-sec ones, which in turn elicited longer time estimates than the 15-sec melodies.

The mean time estimates were very close to the real durations and were also underestimations. Frequency curves of the time estimates made in response to the three melody

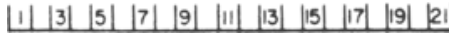
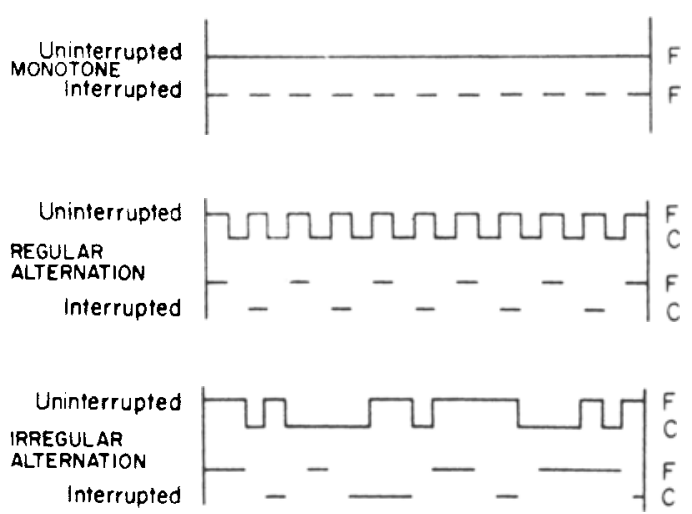

Fig. 1. Graphic display of the melodies. 
Table 1

Menn Times Estimates for Daration, Complexity and Intemption of Melodies

\begin{tabular}{|c|c|c|c|c|c|c|c|}
\hline \multirow[b]{2}{*}{ Real Dur. } & \multicolumn{2}{|c|}{ Uninterrupted } & \multirow[b]{2}{*}{ Ir-Alt } & \multirow[b]{2}{*}{ Mono } & \multicolumn{2}{|c|}{ Internupted } & \multirow[b]{2}{*}{$\bar{x} \bar{x}$} \\
\hline & Mono & $\mathbf{R}_{\mathrm{g}} \mathbf{A l t}$ & & & R-AIt & Ir-AIt & \\
\hline $15 \mathrm{sec}$ & 13.8 & 13.4 & 13.9 & 13.3 & 13.3 & 14.4 & 13.7 \\
\hline $30 \mathrm{sec}$ & 26.6 & 25.9 & 26.0 & 24.7 & 24.7 & 24.8 & 25.5 \\
\hline $45 \mathrm{sec}$ & 36.4 & 38.1 & 39.1 & 35.1 & 36.0 & 36.5 & 36.9 \\
\hline $\bar{x}_{\bar{x}}$ & 25.6 & 25.8 & 26.3 & 24.4 & 24.7 & 25.2 & \\
\hline \multicolumn{2}{|c|}{ Grand Means } & 25.9 & & & 24.8 & & \\
\hline
\end{tabular}

lengths (not presented here) showed that the judgments were positively skewed (tending to underestimation) and widely distributed (having large variances).

Hartley's test showed that the time estimates among the three melody lengths were not homogeneous. However, within each melody length the estimates for order of presentation, complexity, and interruption were homogeneous. A separate, repeated-measurements analysis of variance (after Winer, 1962) was performed on the time estimates for the 15-, 30, and 45-sec melodies, respectively. Each analysis differentiated the effects of the four orders of melody presentation, three degrees of complexity, and two states of interruption. All three analyses showed that there were no statistically reliable differences among the time estimates either as a function of melodic complexity or state of interruption. In the 15-sec analysis there was an order effect $(F=3.45>2.80$ at .05$)$, and in the 45-sec analysis there was an interaction effect of presentation order with melodic complexity $(F=7.74>2.99$ at .01).

\section{CONCLUSION}

The simplest melody received the shortest time estimates, the more complex one longer estimates, and the most complex melody the longest time estimates. But the differences in time estimates were small and not statistically significant. The effects on time estimates of melodic complexity and interruption seem to have been negligible in comparison to the effects of the real durations and the presentation order of the melodies. Perhaps the differences were not statistically significant because the melodies were too close in degree of complexity. Yet greater differences in complexity might have lead to responses as a function of degrees of interest.

The time estimates for the interrupted melodies were shorter than for the uninterrupted melodies, but the differences were not statistically significant. Thus Ss' time estimates did not significantly reflect the fact that the interrupted melodies had only about half the total amount of sound-time as the uninterrupted forms. Perhaps Ss used the durations of the melodies (time spans between the beginnings and endings) as the bases for their time estimates rather than the amount of tone-filled time within the melodies. The rests were the same or shorter durations than the notes; thus the rests might not have been noticed or responded to as "interruptions" of the ongoing melodies. Also, the rests occurred with on-beat regularity; perhaps "the role of the rest as a part of the metrical context ... cannot be an interruption: the meter continues undisturbed whether each of its beats is actually occupied by tones or not [Zuckerkandl, 1956, p. 191]."

The overall underestimation of real time found in the present experiment is quite typical of time estimation studies (see Fraser, 1966; Fraisse, 1963; and Woodrow in S. S. Stevens, 1951). Axel (1924) explained this underestimation by noting that there is a floor to time estimates, zero time, but no ceiling to them. The present experiment was a listening task, and Loehlin (1959) found that listening tasks are usually underestimated. Also, Quasebarth (1924, in S. S. Stevens, 1951) found that passive concentration on a percept leads to underestimation of time while active concentration leads to overestimation. The present experiment's melody-listening task was probably passive.

In summary, absolute time estimates became longer for more complex melodies than for simpler ones and longer for melodies without rests than for melodies with rests. But the differences were small and not statistically significant.

\section{REFERENCES}

AXEL, R. Estimation of time. Archives of Psychology, 1924, 74, 1-72. FRAISSE, P. The psychology of time. New York: Harper \& Row, 1963. FRASER, J. (Ed.) The voices of time. New York: George Braziller, 1966.

GULLIKSEN, $H$. The influence of occupation upon the perception of time. Journal of Experimental Psychology, 1927, 10, 52-59.

LOEHLIN, J. The influence of different activities on the apparent length of time. Psychological Monographs, 1959, 73, No. 474.

QUASEBARTH, K. Zeitschätzung and Zeitauffassung optisch und akustisch ausgefullter Intervalle. Archiv fur die gesamte Psychologie, $1924,49,379-432$. Cited by Woodrow, H. Time perception. In S. S. Stevens (Ed.), Handbook of experimental psychology. New York: Wiley \& Sons, 1951. Pp. 1224-1236.

WINER, B. Statistical principles in experimental design. New York: McGraw-Hill, 1962.

WOODROW, H. Time perception. In S. S. Stevens (Ed.), Handbook of experimental psychology. New York: Wiley \& Sons, 1951. Pp. 1224-1236.

ZUCKERKANDL, V. Sound and symbol music and the external world. Translated by W. R. Trask. New York: Pantheon Books, 1956. NOTES

1. Now at Eastern Middlesex Guidance Center, North Reading, Mass.

2. I am indebted to Walter J. Dowling and Dr. John B. Carroll, as well as Marshall Smith and Drs. Sheldon White and Doris Aaronson for their aid at various stages of this study. 